\title{
Preference for Traditional Medical Care to Orthodox Medical Care Among Secondary School Students in Rural Area of Nigeria
}

\author{
Samson Ayo Deji ${ }^{*}$, Eyitope Oluseyi Amu, Paul Oladapo Ajayi, Taiwo Samuel Ogunleye \\ Department of Community Medicine, Faculty of Clinical Sciences, College of Medicine, Ekiti State University, Ado Ekiti, Nigeria
}

Email address:

Samdeji3@hotmail.com(S. A. Deji)

${ }^{*}$ Corresponding author

To cite this article:

Samson Ayo Deji, Eyitope Oluseyi Amu, Paul Oladapo Ajayi, Taiwo Samuel Ogunleye. Preference for Traditional Medical Care to Orthodox Medical Care Among Secondary School Students in Rural Area of Nigeria.European Journal of Preventive Medicine.

Vol. 9, No. 1, 2021, pp. 14-18. doi: 10.11648/j.ejpm.20210901.13

Received: January 19, 2021; Accepted: January 31, 2021; Published: February 10, 2021

\begin{abstract}
Most rural dwellers of developing countries often patronise unstandardized traditional medical care when they are ill. The study determined the reasons for preference of trado- medical care to standard orthodox medicine among secondary school students in Nigeria. A cross sectional study was carried out in three secondary schools located at Imesi-Ile, Osun State Nigeria. Respondents were recruited by multistage sampling technique. Fifty students each were selected from final year Junior Secondary School class, senior secondary classes 1 and 2 without gender bias. Pre-tested semi- structured questionnaires were employed to elicit data on their choice of preference for traditional medicine to orthodox medic-care. The results were analysed using SPSS version 20. Most respondents were females, 77 (51.3\%). About 113 (75.3\%) reported that they preferred traditional care to orthodox treatment because the later was too expensive for them to afford. About 108 (72\%) adopted traditional medicine because of parents' choice. Those who reported easy accessibility to traditional medicine as a choice for its preference were $85(56.6 \%)$, while $78(52 \%)$ believed that traditional medicines cure faster than orthodox, others reported they have been using traditional medicine from childhood (60.7\%), and for some traditional medicine was preferred due to their friend's choice (54.0\%). Most youths preferred trado-medical care due to high cost of orthodox medicine and wrong perceptions. Proper education to correct wrong notions among youths and improving the economic power of the people will help the community.
\end{abstract}

Keywords: Orthodox, Medicine, Preference, Students, Traditional

\section{Introduction}

Developing countries over time have been worst hit with poor medical treatment resulting into increased mortalities and morbidities especially among the vulnerable groups such as children and pregnant women. [1] The youths, who constitute a significant proportion of the entire population are not spared of these problems. In most rural communities where traditional beliefs such as the use of local concoctions to treat sicknesses are upheld, the patronage of local unstandardized traditional medical care increases compared to public orthodox health facilities centres at their domain. [2] Traditional medicine (also known as indigenous or folk medicine) comprises the traditional methods used in treating diseases that developed over generations within various societies before the era of modern medicine. [3] The World Health Organization (WHO) defines traditional medicine as "the sum total of the knowledge, skills, and practices based on the theories, beliefs, and experiences indigenous to different cultures, whether explicable or not, used in the maintenance of health as well as in the prevention, diagnosis, improvement or treatment of physical and mental illness. [3] Traditional African medicine is an alternative medicine discipline involving indigenous herbalism and African spirituality, typically involving diviners, midwives, and herbalist. [3, 4]. In most rural settings of developing countries where accessibility to standard orthodox medicine is limited, the prevalence of local traditional medicine increases. [3] According to the World Health Organization, despite the introduction of orthodox medicine by the Europeans who colonized Africa, about $80 \%$ of Africans 
still use traditional medicines, especially herbal medicines for their primary healthcare needs. [5] It is reported that in some African countries like Ghana, Mali, Zambia and Nigeria, about $60 \%$ of children with high fever resulting from malaria use herbal medicine as its first line of treatment. [3] In Ghana, about $70 \%$ of the population domicile in rural areas depends primarily on traditional medicine. [3] It has been reported that about 27 million South Africans (usually the black South Africans) use traditional medicine to treat a variety of of ailments. [3] It was also reported that traditional medicine has been used in the treatment of convulsion in Tanzania, a practice common in most African countries. [3] In some cases, patients use both traditional medicine and modern orthodox medicine at the same time. It was reported that a significant number of hypertensive patients receiving conventional treatment at the tertiary health facility in Lagos, Nigeria also use local traditional medicine at the same time. [3]

It is worthy of note that patronage of traditional medicine has also been reported in developed countries such that approximately $20 \%$ of people in the United States of America use herbal products for various health challenges. [6]

Practitioners of traditional African medicine claim to be able to cure various disease conditions ranging from non communicable diseases such as cancers, psychiatric disorders, high blood pressure, epilepsy, and communicable diseases like cholera, venereal diseases, fungi skin infections, fever, urinary tract infections, among others. [4] It is common practice to see those affected with these diseases queuing at the houses of traditional healers to receive one form of herbs or the other to treat their ailments. [5]

Orthodox medicine is a system in which medical doctors and other trained healthcare professionals (such as nurses, pharmacists and therapists) treat diseases using standardized drugs, radiation, or surgery. [7] Also called allopathic medicine, biomedicine, conventional medicine, mainstream medicine and western medicine. The conventional practice in most developed countries of the world is to access healthcare services through the route of orthodox medical care. [6]

In most developing countries particularly in rural areas of Africa, traditional health care is preferred by an estimated $80 \%$ of the populace for a number of reasons including availability, perceived efficacy, lack of western health care and most importantly because it is an integral part of many African cultures. [3] In Nigeria, the current population of rural dwellers is $49.5 \%$ with most of the communities underdeveloped without adequate health facilities. [2] However, literature also exists indicating that most people in some parts of Africa also prefer the utilization of orthodox medical care especially where there are easy accessibilities to the basic health facilities at their domain. [3, 4] Preference for orthodox medical care have been reported in some part of Africa countries due to factors such as perceived toxicity of traditional medicine, and religious beliefs (most Christians do not believe in traditional medicine etc. [3, 5]

Traditional medical system in low income countries remain the first point of contact by the people particularly in rural communities where patients may need to travel longer distances to access standard orthodox medical care. Although the role of traditional birth attendants (TBAs), as a fraction of traditional medical care, is recognized in many primary health care system in most low income countries. However, other types of traditional practitioners exist whose practices do not measure up to the required standard of hygiene as seen in orthodox medical care. [2] Many ailments and injuries that could have been easily managed are diverted to traditional healers who in the process of treating their clients leave them worse medically than at first presentation. [4] In most cases when the traditional healers' hands off the management of their patients, many irreparable damages would have taken place in some vital organs of the body due to usage of unstandardized dose regimen of their herbal drugs. Such practices have the tendency of increasing morbidities and mortalities among patients.

Low patronage of most public health facilities in rural villages exists in developing countries like Nigeria. [5] This informed the reason why the study was carried out to determine the reasons behind the preference of traditional medical care to orthodox medical care among young people in a rural community of Nigeria. Most studies carried out in many rural areas of developing countries often evaluate the quality of care rendered through public health facilities with little or no reference to why a greater number of patients patronise local traditional homes for medical care especially in the rural communities.

\section{Materials and Methods}

The study design was a cross sectional survey conducted in Imesi Ile, a rural community of Osun state Nigeria. Osun State is one of the states in the south western zone of Nigeria. Imesi Ile community is majorly agrarian with a rural comprehensive health centre and a private hospital as health facilities rendering standard orthodox medical care to the dwellers. Most of the citizens are Yoruba with minority of other ethnic groups from different parts of the country, Nigeria. There are public and private owned primary and secondary schools. The target population in the study was the young people in Osun State and the study population focused on secondary school pupils in the upper classes comprising Junior secondary school class three, senior secondary school classes one and two.

\subsection{Sample Size Determination}

The sample size was determined using the formula for single proportion.

$$
\mathrm{N}=\frac{Z^{2}(\mathrm{pq})}{d^{2}}
$$

Where,

$\mathrm{Z}=$ standard normal deviate at 1.96 at $95 \%$ confidence interval.

$\mathrm{p}=$ prevalence of $10 \%[7]$

$q$ is $(1-p)$

$\mathrm{d}$ is the precision at 0.05

$$
\mathrm{N}=\frac{1.96 \times 1.96(0.1 \times 1-0.1)}{0.05 \times 0.05}=138.3
$$


The sample size was rounded up to 150 to accommodate or make allowance for non-response adding $10 \%$ of the calculated sample size.

\subsection{Sampling Technique}

A multi staged sampling technique was used to identify and recruit respondents.

$1^{\text {st }}$ Stage: Three secondary schools were selected by simple randomly sampling.

$2^{\text {nd }}$ Stage: Cluster sampling method was used in selecting three classes which included Junior secondary school class 3, senior secondary school classes 1 and 2,

$3^{\text {rd }}$ Stage: Fifty respondents were selected by simple random sampling method through balloting from each of the classes with no gender bias.

Pre-tested semi-structured questionnaires were employed to elicit data from the respondents.

Information regarding the reasons for preference of traditional medicine to orthodox treatment was obtained.

The result was analysed using software of Statistical Package for Social Sciences (SPSS) version 20. Continuous variables were summarised using descriptive statistics. Level of statistical significance was set at $\mathrm{p}<0.05$.

Respondents were recruited after informed consent was taken from each of them before the onset of the study and participation was made voluntary. The research was conducted in accordance with the declaration of Helsinki. Participants were assured of confidentiality of data collected from them.

\section{Results}

From table 1 majority of the respondents spanned across middle to older adolescents $(93.4 \%)$ Most participants in the study were females (51.3\%) Majority $150(66.4 \%)$ were in the upper arms of the secondary school.

In table 2, about $72.0 \%$ adopted traditional medicine because of parents' choice. Those who reported easy accessibility to traditional medicine as a choice for its preference were $56.6 \%$. While $52.0 \%$ believed that traditional medicines cure faster than orthodox, others reported they have been using traditional medicine from childhood $(60.7 \%)$, and for some traditional medicine was preferred due to their friend's choice $(54.0 \%)$.

Table 3 showed the different diseases the respondents reported to have contacted and treated in the last five years prior to the time of the study. The most common disease reported to have been contacted among respondents was typhoid fever $(14.0 \%)$ which results mostly due to poor personal hygiene.

Table 1. Socio-demographic characteristics of respondents.

\begin{tabular}{ll}
\hline Variables & $\mathbf{n}(\mathbf{\%})$ \\
\hline Age & $6(4.3)$ \\
$10-14$ & $141(93.4)$ \\
$15-19$ & $3(2.3)$ \\
$20-24$ & \\
Sex & $73(48.7)$ \\
Male & $77(51.3)$ \\
Female & \\
Class & $50(33.3)$ \\
JSS 3 & $50(33.3)$ \\
SSS1 & $50(33.3)$ \\
SSS2
\end{tabular}

*JSS (Junior Secondary School)

*SSS (Senior Secondary School)

From table 1 majority of the respondents spanned across middle to older adolescents (93.4\%) Most participants in the study were females (51.3\%) Majority 150 (66.4\%) were in the upper arms of the secondary school.

Table 2. Reasons for preference of patronage of traditional medical care to orthodox medical care.

\begin{tabular}{|c|c|c|c|c|c|}
\hline Variables & $\begin{array}{l}\text { Strongly agree } n \\
(\%)\end{array}$ & $\begin{array}{l}\text { Agree n } \\
(\%) \\
\end{array}$ & $\begin{array}{l}\text { Undecided } \\
(\%)\end{array}$ & $\begin{array}{l}\text { Disagree } \\
(\%)\end{array}$ & $\begin{array}{l}\text { Strongly Disagree n } \\
(\%)\end{array}$ \\
\hline High Cost of orthodox medicine & $49(32.7)$ & $64(42.7)$ & $6(4.0)$ & $27(18.0)$ & $4(2.6)$ \\
\hline Traditional medicine preferred by parents & $43(28.8)$ & $65(43.3)$ & $11(7.3)$ & $26(17.3)$ & $5(3.3)$ \\
\hline Easy accessibility to traditional medical care & $41(27.3)$ & $44(29.3)$ & $10(6.7)$ & $33(22.0)$ & $22(14.7)$ \\
\hline Believed traditional medicine cures faster & $38(25.3)$ & $40(26.7)$ & $18(12.0)$ & $35(23.3)$ & $19(12.7)$ \\
\hline Have used traditional medicine from childhood & $45(30.0)$ & $46(30.6)$ & $16(10.7)$ & $24(16.0)$ & $19(12.7)$ \\
\hline Preferred traditional medicine because offriend's choice & $39(26.1)$ & $42(28.0)$ & $29(19.3)$ & $23(15.1)$ & $17(11.3)$ \\
\hline
\end{tabular}

In table 2 , about $72.0 \%$ adopted traditional medicine because of parents' choice. Those who reported easy accessibility to traditional medicine as a choice for its preference were $56.6 \%$. While $52.0 \%$ believed that traditional medicines cure faster than orthodox, others reported they have been using traditional medicine from childhood $(60.7 \%)$, and for some traditional medicine was preferred due to their friend's choice $(54.0 \%)$.

Table 3 showed the different diseases the respondents reported to have contacted and treated in the last five years prior to the time of the study. The most common diseases reported to have been contacted among respondents was typhoid fever
$(14.0 \%)$ which results mostly due to poor personal hygiene.

Table 3. Respondents' list of communicable diseases previously contacted and treated in the past 5 years.

\begin{tabular}{ll}
\hline Diseases & $\mathbf{n} \%$ \\
\hline Typhoid fever & $21(14.0)$ \\
Scabies & $5(3.5)$ \\
Tuberculosis & $5(3.5)$ \\
Measles & $15(10)$ \\
Chicken pox & $12(8)$ \\
Sexually transmitted diseases & $3(2.5)$ \\
No response & $89(58.4)$ \\
\hline
\end{tabular}

*Multiple responses allowed 


\section{Discussion and Conclusion}

Proper care of the sick becomes very importance if the overall goal of reducing the rates of morbidities and mortalities will be achieved in any community, hence the choice of health care services accessed by patients becomes very crucial. [6] In this study, most respondents gave several reasons for their preference of traditional medicine to orthodox medicine. This is commoner in most rural settings of developing countries where cultural values have largely influenced their choices of living standards including accessing health care services. [4] The rate of recovering from illness is a function of adequate care received at health care centres patronised by patients. This study determined the reasons influencing the preference of traditional medicine to orthodox medicine by students in rural community of Imesi Ile, Osun State, Nigeria. In this study most of the study participants (about three quatre) were in the higher levels of secondary school with divergent opinions. This is however different from a study conducted in the rural communities that examined adult rural dwellers' patronage of traditional medicine. [2]

In this study about three quarter of the young people reported high cost of orthodox medical care as their choice of preference to traditional medical care. This is in corroboration with studies conducted in African countries that reported above half of respondents' preference of tradomedicare due to high costs of orthodox medicine. [7] In most developing countries with poverty as a major problem, the cost of orthodox medical care becomes a hindrance to accessing quality health care services. [8] The high cost of treatment appears to be the top on the list of reasons that influenced the choice of traditional medical care by the students. The cost of orthodox medicine is generally higher than herber medicines in developing countries. A study carried out by K A Muhammed in northern Nigeria, noted that poor political will has resulted in the abandonment of many primary health centres by patients who may have to pay more than usual to access orthodox health care.[9]

If the government will subsidize the rate of medical care through extending the national health insurance scheme to rural dwellers, there is bound to be an increase in the patronage of public health facilities. Poverty is generally wide spread among most developing countries which is predominant in rural communities' with poor infrastructural amenities without good health care services that can improve the health status of the people.

Most people live below one dollar per day in many poor developing countries and are often hit with malnutrition leaving them vulnerable to various infectious diseases. The scarcity of funds most often make people of low socio economic status patronize local traditional medical care whose services are cheaper compared to orthodox medicine.

Above half of the respondents in this study reported easy accessibility to traditional medical care as a reason why they patronize traditional medicine compared to orthodox medicine. This is in agreement with a study conducted by $\mathrm{K}$
P Osemene etal who reported that above half of the patients studied made the choice of accessing traditional medicines due to easy accessibility. [10]

In most rural areas there are no good proximity of health facility centres to the people in their communities. The study area had only one government owned health centre serving the entire community not centrally located. Most sick people would naturally patronize nearby traditional healers for treatment caring less of the quality of services they receive.

One of the beliefs of most rural community dwellers is that traditional medicine cures faster than orthodox medicines. This was found in the study as a significant proportion above one third $(68.0 \%)$ believed that traditional medicines cure faster than orthodox medicines. This finding was however different from a study conducted in an urban town in Nigeria which reported that about three quarter believed that the use of orthodox medicine is more effective compared to traditional medicine. [11]

In most developing countries traditional beliefs affect their attitude to lifestyles and play a key role in the choice of care they would prefer when they are ill. [10]

Above half of the respondents reported that they preferred traditional medicine to orthodox medical care because their parents had been using traditional medicine all through their childhood days with no visible consequences. Prolong usage of traditional medicine by some of the respondents had affected the right perception that orthodox medicine which is more scientific and globally acceptable is less inferior to traditional medicine. [12]

Most of the respondents reported that their choice of traditional medicine was informed by their friends and peer groups who most often patronized traditional medicine as an option of treatment whenever they took ill. The impact of peer pressure and friends can be very strong especially when it comes to taking crucial decisions in the choice of accessing better health care services. [13]

The advocacy for orthodox medical care is of paramount importance especially in developing countries where there are low standards of living which have often contributed to increase burden of infectious diseases that cannot receive proper treatment through traditional medical care. [14]

The most prevalent communicable diseases respondents claimed to have been exposed to in the last five years until the time of the study was typhoid fever which is transmitted by faeco oral route.

It is not unlikely most of the herbal concoctions used as medicines by traditional healers would have been contaminated due to poor preparations in unsanitary conditions which could favour the transmission of several communicable diseases. [15] In a typical rural African setting, less attention is given to proper hygiene even in the preparation of daily food. The choice for alternative medicine apart from the globally acceptable orthodox medicine does not go without its challenges. [16]

The choices of using traditional Medicare by respondents were based on several reasons which reflected their ignorance of the importance of orthodox medicine as the best 
option of managing disease conditions. The negative perceptions of the respondents about orthodox medicine contributed to the low patronage of public health care facility in the area. It is therefore, recommended that series of public enlightenment and sensitization campaigns on the significance of orthodox medicine should be carried out on regular basis to dwellers in the community.

Parents of pupils in the study area will need to be educated more on the benefits of patronizing orthodox Medicare which is more scientific and safe, with standard regulations. This should also be included in the curriculum of health education for the students stressing the importance of orthodox medicine, and discourage traditional Medicare that may be detrimental to their overall health of the people. Also there should be political commitment of governments in various strata to improve the living standards of people through provision of adequate infrastructural amenities which will help to minimise the risk of disease transmission and as well encourage people to patronize orthodox medical care.

\section{Competing Interests}

There was no competing interest declared throughout the course of the research work.

\section{References}

[1] Poverty and poor health- world bank. Dying for change: Poor people' sexperience of health and ill-health. Siteresources.

worldbank.org/NTPAH/Resources/Publications/dying for change. And poor health in the least developed countries. 2001. Accessed on $29^{\text {th }}$ July 2020.

[2] Aborigo Raymond Akawire; Allotey Pascale; Redpath Daniel. The traditional healer in obstreticcare: a persistent wasted orpotunity in maternal health. SocSci Med Pubmed. 2015. 13 (3); 59-66.

[3] Abdullahi, AA (2011). Trend and Challenges of Traditional Medicinein Africa.. African Journal of Traditional, Complementary and Alternative Medicines. 8 (5S): 115-23).

[4] Van Niekerk J. Trditional healers formalized? SAfr Med J. 2012: 102; 105-6.
[5] World Health Organization. WHO traditional medicine strategy 2002-2005.

[6] Bent S. Herbal medicine in the United States review of efficacy, safety, and regulation: grand Rounds at University of California, San Francisco Medical Centre. Journal of General Internal Medicine. 2008: 23 (6) 854859.

[7] Healthcare Access in Rural Communities Introduction-Rural Health. http//www.ruralhealthinfo.org/topics/healthcareaccess. Accessed online on July 29, 2020.

[8] Rhoda G Hughes. Patients safety and quality: An evidenced based handbook for Nurses. US Agency for healthcare research and quality. 2008.

[9] Kurfi Abubakar Muhammed. Assessment of barriers to utilization of primary health care services in Batsari Local Government Area of Kastina, Nigeria. MPH Disseratition..2011.

[10] K P Osemene, A A Elujoba, M O Ilori. A comparative assessment of herbal and orthodox medicines in Nigeria. Research Journal of Med. Sciences. 2011; (5) 280-285.

[11] C B Duru, K C Diwe, K A Uwakwe, C A Duru et al. Comnined orthodox and traditional medicine use among housholds in Orlu, ImoState, Nigeria: Prevalence and Determinants. World Journal of Prvenetive Medicine. 2016. (4) 5-11.

[12] Ladele AA, Bisi-Amosun OO. Level of utilization of traditional and orthodox medicines by Rural Dwellers in IleOgbo Community of Osun State, Nigeria. Journal of Agricultural Extension. 2014; 18 (1): 155-168.

[13] Aderibigbe SA, Agbaja SR, Bamidele JO. Determinatants of utilization of traditional bone setter in Ilorin, North Central Nigeria. J. Prev. Med. HYG., 2013; 54: 35-40.

[14] Hori S, Mihaylov I, Vasconcelos JC, McCoubrie M. Patterns of complementary and alternative medicine use amongst outpatients in Tokyo, Japan. BMC Complementary and Alternative, 2008; 8: 14. doi: 10.1186/1472-6882-8-14.

[15] Bamidele JO, Adebimpe WO, Oladele EA. Knowledge, Attitude, and use of Alternative Medical Therapy Amongst Urban Residents of Osun State, Southwestern Nigeria. Afr. J. Trad. CAM, 2009; 6 (3): 281-288.

[16] Onyiapat JLE, Okoronkwo IL, Ogbonnaya NP. Complementary and Alternative Medicine use among Adults in Enugu, Nigeria. BMC Complementary and Alternative Medicine, 2011; 11 (1): 19. doi: 10.1186/1472-6882-11-19. 